\title{
La necesidad de una ley integral para hacer frente a la violencia de género en España (LO 1/2004)
}

\section{Perla Elizabeth Bracamontes Ramírez}

\author{
${ }^{1}$ Universidad de Guadalajara, \\ Guadalajara, México, \\ correo electrónico: \\ perla.bracamontes@gmail.com
}

\begin{abstract}
Resumen
Profundizar en un tema como el de la violencia de género no es tarea fácil. Dada la magnitud y la preocupación que existe por el fenómeno, éste ha pasado a ocupar un importante puesto en el panorama internacional, sociabilizándose el rechazo a este tipo de conductas y fomentándose iniciativas legislativas para su erradicación. Precisamente el Estado español introdujo la Ley Integral (LO 1/2004) como instrumento novedoso de solución contra la violencia generada hacia las mujeres, por el simple hecho de ser mujeres, implementando una serie de medidas integrales, multidisciplinares y con carácter transversal para atender, prevenir, sancionar y erradicar la violencia de género, convirtiéndose esta ley en un referente mundial para erradicar el fenómeno que daña, discrimina y mata a mujeres.
\end{abstract}

Palabras clave: violencia de género, ley integral LO 1/2004, discriminación positiva 


\begin{abstract}
Delve into a topic like the gender violence is not an easy task. Given the magnitude and concern that exist about the phenomenon, it has come to occupy an important position in the international arena, socializing the rejection of this kind of conducts and encouraging legislative initiatives in order to eradicate it. Precisely, the Spanish State introduced the Integral Law OL 1/2004 as a new solution tool against generated violence to the women, simply because they are women, implementing a series of integral, multi-disciplinary and cross-cutting measures to attend, prevent, punish and eradicate the gender violence, converting this law in a global reference for eradicate the phenomenon that damages, discriminates and kills to women.
\end{abstract}

Keywords: violence, integral law OL 1/2004, positive discrimination

RECEPCIÓN: 17 DE FEBRERO DE 2015 / ACEPTACIÓN: 13 DE AGOSTO DE 2015

\title{
La violencia contra las mujeres españolas asentada sobre el dominio patriarcal y la necesidad de combatirla
}

Desde hace años las mujeres españolas se han encontrado inmersas en el fenómeno de la violencia generada por los hombres, que reproducen patrones de conductas machistas basadas en la cultura del patriarcado que subordina, discrimina, niega e invisibiliza lo 
femenino. Para Añón (2005: 43), el patriarcado ha sido uno de los términos empleados:

Para dar cuenta del sistema de exclusión, opresión [...] y dominación de las mujeres; pues la sujeción de las mujeres por parte de los hombres es sistemática y no individual y responde a una determinada relación de dominación social y política, en que los hombres individuales participan y se benefician en las relaciones con las mujeres individuales.

La violencia contra las mujeres ocurre en un contexto cultural patriarcal donde el control y sometimiento de la mujer ha sido no sólo tradicionalmente tolerado sino legitimado. Por ello, la violencia de género tiene cimientos en la estructura de la sociedad patriarcal, propagando esta ideología desde el nacimiento y a lo largo de la formación del individuo como persona (Juárez, 2002: 6; Kaufman, 1989: 28).

En este sentido el patriarcado se ha establecido históricamente como fuente de poder social que resulta de la subyugación de las mujeres por parte de los hombres (Lagarde, 1999: 11) y para conservarlo se justifica estableciendo prácticas que conllevan a la violencia de género dispersándose como agente socializador. Provocando así un aumento constante de mujeres muertas o maltratadas por parte de sus maridos, exmaridos, parejas, exparejas, novios o exnovios. 
El trabajo de las organizaciones de mujeres españolas para combatir la violencia sobre las mujeres

El conocimiento del aumento de víctimas por violencia de género en España en el periodo de 1999 al 2003, alarmó a las organizaciones de mujeres que emprendieron acciones sociales de inconformidad por este tipo de conductas reprobables, señalando que las leyes y reformas legislativas no son del todo efectivas sumando los problemas de coordinación entre las instituciones públicas (Montalbán, 2006: 48), motivo por el cual reclaman al gobierno una ley nacional que emprenda medidas desde una perspectiva integral que contenga acciones legales, sociales y políticas para prevenir, atender y eliminar la violencia de género que afecta en mayor o menor grado a las mujeres, limitando el goce de sus derechos esenciales.

Asimismo, exigían que la iniciativa de Ley Integral para contrarrestar el fenómeno de la violencia de género, a través de medidas integrales y multidisciplinares, contará con el respaldo, coordinación y cooperación de las instituciones gubernamentales responsables de atender a las víctimas de la violencia machista; es decir, se pretendía que la actuación institucional fuera de manera transversal, realizada por profesionales en materia de género y derechos humanos y aplicar los protocoles de actuación para garantizar la correcta aplicación de las medidas integrales, así como evitar la doble victimización. También insistían que la Ley Integral contemplara los siguientes objetivos²: 
a) Promover el principio de igualdad, para la

Integral. Vid. Red de organizaciones feministas contra la violencia de género, aplicación de leyes con un criterio no sexista Madrid, 2001, págs 1-3. www. e igualitario. Cabe mencionar que este obje-

redfeminista.org tivo fue materializado posteriormente a través de la Ley Orgánica 3/2007, de 22 de marzo, para la igualdad efectiva de mujeres y hombres.

b) Reconocer que la violencia contra la mujer en el ámbito familiar es una manifestación de violencia de género. Se pretendía insertar el concepto de violencia de género en la legislación española, y que se tipificara el delito de violencia de género en el Código Penal, con la finalidad de diferenciar que la violencia hacia las mujeres ya no será sancionada por las reglas punitivas del delito de violencia doméstica.

c) Medidas legales necesarias, asistenciales y de educación para atajar las causas de la violencia, con especial observación al factor cultural y de sociabilización desigualitaria entre hombres y mujeres, implícitamente señalado con el concepto de violencia de género. En este punto, se apostaba por la necesidad de reformar la legislación española y las políticas públicas, con perspectiva de género, para garantizar las medidas integrales para contrarrestar la violencia de género.

d) La creación de casas de acogida con un tratamiento integral y multidisciplinar para mejorar la atención a las mujeres víctimas de la violencia de género.

e) Legislar el alejamiento automático de los maltratadores. Con la intención de acelerar las medidas cautelares para pro- 
teger a las víctimas y evitar nuevos ciclos de violencia, y para ello se tendría que modificar CP y la LECrim.

f) La creación de una fiscalía especial contra la violencia.

g) El trabajo conjunto del Gobierno con las asociaciones de mujeres.

h) Campañas publicitarias, dirigidas a no mostrar a la mujer como víctima, descalificando las conductas discriminatorias y machistas.

i) Creación de planes de educación con programas impartidos por especialistas en materia.

j) Garantizar el efectivo derecho de información de una vida libre de violencia. A través de los servicios, organismos de las Administraciones Públicas para atender los casos de violencia.

k) Ayudas públicas de carácter económico para mujeres dependientes del agresor.

1) Una jurisdicción especial que permita que un solo juzgado dicte medidas civiles (separación matrimonial y pensión alimenticia) y penales (denuncia por malos tratos) para la protección a la víctima. Para ello, se tendría que modificar la Ley Orgánica del Poder Judicial y la Ley de Demarcación y Planta Judicial.

m) Normas laborales que faciliten la integración laboral en otras ciudades a aquellas mujeres que ante una situación de peligro se han visto obligadas a dejar su domicilio y su trabajo. 
Para llevarse a cabo se tendría que modificar el Estatuto de Trabajadores y la Ley General de Seguridad social.

n) La asistencia jurídica gratuita a todas las víctimas. Pretendiendo fortalecer la defensa y orientación jurídica en los procesos judiciales y administrativos, por lo cual se modificaría la Ley 1/1996, de 10 de enero, de Asistencia Jurídica Gratuita.

Estas propuestas fueron diseñadas siguiendo las recomendaciones de la Organización de las Naciones Unidas para Eliminar la Violencia sobre las Mujeres, ya que constituye un obstáculo para garantizar la igualdad, progreso y paz, además de estipular que este tipo de violencia contiene:

Condicionantes culturales basados en la superioridad del género masculino sobre lo femenino, vulnera además el derecho a la dignidad de la persona y el libre derecho de la personalidad, la vida, la libertad, la seguridad, la integridad física, derechos consagrados en la Constitución Española arts. 10,14,17 CE (Peramato, 2007: 2).

Este punto de vista es una realidad social, encontrándose marginadas las mujeres españolas del pleno goce de sus derechos fundamentales, además de apuntar que la violencia que se ejerce contra ellas y con más frecuencia en el ámbito de la pareja es una conducta que propicia y resalta la desigualdad entre hombres y mujeres. Por ello, como bien indica Pérez (2008: 18) que para contrarrestar 
la violencia de género deben buscarse respuestas integrales eficaces y concluyentes para dar soluciones que serán capaces de neutralizar las posiciones de poder y dominio que a lo largo de la historia se han venido produciendo del hombre sobre la mujer.

Por consiguiente, ante la presión del movimiento feminista y de organizaciones de mujeres, el gobierno español en el 2004 aprueba por unanimidad la Ley Orgánica 1/2004, de 28 de diciembre, de Medidas de Protección Integral contra la Violencia de Género (LO 1/2004) con la intención de regular por ley la atención, prevención, sanción y erradicación de la violencia contra las mujeres a nivel nacional, a través de un tratamiento integral y multidisciplinar, cabe resaltar que las propuestas diseñadas por el movimiento de mujeres mencionadas anteriormente fueron incorporadas al texto de la LO 1/2004 a través de un trámite especial de audiencia en el Parlamento donde participaron asociaciones, organizaciones de mujeres y expertos en materia, con la intención de que la sociedad se sienta parte y responsable del proceso, contribuyendo en adecuar y mejorar este instrumento legal para luchar contra la violencia sobre las mujeres por razón de género.

\section{La Ley Integral (LO 1/2004). Instrumento novedoso de solución}

La Ley LO 1/2004, entiende la magnitud del problema social, que presenta la violencia contra la mujer y que infringe derechos fun- 
damentales como la vida, la igualdad, la libertad, la seguridad, la no discriminación, todo ello avalado por la Constitución Española (Iñigo, 2005: 13). Precisamente esta ley se empeña en dar una prioritaria solución utilizando medidas integrales (siguiendo el ejemplo de aplicación de algunos países latinoamericanos y por primera vez se aplica esta normativa en el continente europeo) para abordar la violencia contra la mujeres, delimitando su ámbito de aplicación a la violencia ejercida por el hombre contra la mujer con la que tiene o ha tenido un vínculo afectivo o de análoga relación. Pretendiendo establecer la igualdad entre hombres y mujeres, brindando así respuestas globales contundentes para combatir la violencia de género considerada en su exposición de motivos como:

Un símbolo más brutal del la desigualdad existente en la sociedad. Se trata de la violencia que se dirige sobre las mujeres por el hecho mismo de serlo, por ser consideradas, por sus agresores, carentes de los derechos mínimos de libertad, respeto y capacidad de decisión (LO 1/2004).

En este sentido Sanz-Díez y Moya (2005: 13) comentan que la ley es un acierto por proteger en especial a la mujer, ya que se encuentra sometida a situaciones de dominación por parte de su pareja o ex pareja, donde la gran mayoría utilizan la violencia para demostrar su poder y control. En este mismo sentido Metre (2005: 35) indica que la ley integral asume la agresión a las mujeres como una violencia estructural fundada en normas y valores sociales que en- 
cuentran su fundamento en las relaciones desiguales y jerarquizadas entre los sexos.

De acuerdo con Ibáñez (2007: 119-120) el objeto de la ley es actuar contra la violencia hacia la mujer en el ámbito de la familia estableciendo para ello una serie de medidas de protección integral, con fines de prevención, sanción y erradicación. Por ello el objetivo de esta norma es dar una respuesta global a la violencia que se ejerce sobre las mujeres (Martínez, 2005: 33).

Por consiguiente estamos de acuerdo con los autores al considerar que el objetivo de la ley parte de la afirmación de que la violencia de género es una manifestación de la discriminación, la desigualdad y las relaciones de poder de los hombres sobre las mujeres. Recordando que los malos tratos que reciben las mujeres en el seno del hogar se originan por la situación de desigualdad, ya que los hombres consideran a las mujeres como bienes propios y su fuente de poder, y para conservarlo crean un escenario lleno de control y sometimiento. Como bien indica Camarero (2006: 17) la violencia contra las mujeres ha sido y es un instrumento para su dominación.

Ante esta situación la presente ley establece medidas de protección integral, consistentes en prevención, sanción y erradicación de las conductas que generan la violencia, así como brindar asistencia a las víctimas, además de fortalecer a los poderes públicos de instrumentos eficaces en el ámbito educativo, servicios sociales, sanitario, publicitario y mediático, e instaurando nuevos órganos e instituciones con el objetivo de abastecer la atención 
adecuada a este fenómeno y, en especial, se centra en algunas modificaciones de orden jurídico, procesal y judicial, todo encaminado a garantizar el bienestar y derechos de toda la ciudadanía.

\section{Objeto de la Ley Integral (LO 1/2004)}

Como bien indica Montalbán (2005: 61), por el objeto de una ley ha de entenderse el conjunto de medidas jurídicas que se adoptan para regular una realidad social que se encuentra afectada. La presente ley pretende ser el principal instrumento jurídico de la lucha contra la violencia de género, estableciendo medidas de protección integral cuya finalidad es prevenir, sancionar y erradicar esta violencia, y prestar asistencia a sus víctimas (art.1.2 LO 1/2004).

Por primera vez se ofrece una definición legal aplicable en toda la jurisdicción española del concepto de género considerando que dicha violencia se ejerce contra la mujer como:

Manifestación de la discriminación, la situación de desigualdad y las relaciones de poder de los hombres sobre las mujeres, se ejerce sobre éstas por parte de quienes sean o hayan sido sus cónyuges o de quienes estén o hayan estado ligados a ellas por relaciones similares de afectividad, aun sin convivencia (art. 1.1 LO 1/2004).

También señala los determinados tipos de violencia contemplando todo acto de violencia física y psicológica, incluidas las agresiones 
a la libertad sexual, las amenazas, las coacciones o la privación arbitraria de libertad (art.1.3 LO 1/2004).

\section{Ley con carácter integral (LO 1/2004)}

La LO 1/2004 se considera integral, ya que intenta abordar el problema de violencia de género, que por su carácter transversal afecta a todos los sectores de la sociedad. Pretendiendo realizar un estudio profundo sobre las causas generadoras del problema y con la posibilidad de ofrecer respuestas legales multidisciplinares.

Por lo que señala Montalbán (2005: 285) "es una ley reformadora de leyes que abarca a distintas jurisdicciones" tanto administrativa, laboral, civil y penal. Cabe mencionar que en España ya se utilizaban leyes que comprendían varías jurisdicciones como la ley de menores y unificación de la jurisdicción social y civil en los Juzgados Mercantiles.

Para Palomar (2005: 185) la Ley Integral supone un intento de abordar un problema social desde una perspectiva "completa, genérica y con carácter de integral en el que las políticas sectoriales y la actuación de las distintas administraciones públicas buscan una coordinación horizontal-vertical".

Concordamos con la opinión Palomar ya que la ley por su carácter transversal necesita sin falta una verdadera coordinación en la información, y consensos de todos los funcionarios en sus respectivas competencias para la eficacia y rapidez de las medidas que se deban implementar a favor de las víctimas de violencia de género. 
En efecto la Ley Integral se considera importante ya que brinda respuestas institucionales de carácter global, con objetivos de proporcionar medidas educativas, de sensibilización, contra la publicidad ilícita, de prevención, de protección social y económica, de tutela institucional, penal y judicial ${ }^{3}$ para contrarrestar la violencia de

${ }^{3}$ Contemplado en la Exposición de Motivos, donde la Violencia de Género: "Se enfoca por la Ley de un modo integral y multidisciplinar, empezando por el proceso de socialización y educación", género que está presente en la sociedad.

LO 1/2004.

\section{Novedades generales incorporadas en} la Ley Integral (LO 1/2004)

La Ley Integral constituye un novedoso instrumento normativo que pretende combatir la violencia de género que en especial sufren las mujeres como acto de discriminación (Iñigo, 2005: 22), como consecuencia de los patrones socioculturales situándola en una posición de subordinación y desventaja con respecto al hombre. Así la ley plantea proteger a las víctimas incorporando respuestas multidisciplinares novedosas:

- Se considera la primera Ley Integral, en los alcances de la Unión Europea para combatir la lacra social que mantiene vigente la violencia de género.

- Se establece de forma general en la legislación española el concepto de género.

Se implementan medidas de acción positiva, con la finalidad de hacer efectivos los derechos fundamen- 
tales de los ciudadanos a gozar de una plena igualdad, libertad, derecho a la vida, seguridad y a la no discriminación por razón de sexo en la aplicación de la ley. Un claro ejemplo es la implementación por primera vez de la acción positiva en el ámbito penal (art. 153.1 CP).

- Se establecen varias modificaciones en la legislación penal, civil y procesal acordes con las medidas integrales con perspectiva de género, para agilizar la erradicación de la violencia por razón de género.

Recoge en un solo cuerpo legal todos los aspectos que abarca las distintas causas de la violencia contra las mujeres mediante un enfoque multidisciplinar, ofreciendo medidas de prevención, sensibilización e intervención en el ámbito educativo, penal, institucional y judicial, con el propósito de garantizar los derechos de las víctimas a través del acceso a la información, asistencia sanitaria, protección en el ámbito social, recuperación de las víctimas y apoyo económico. Debiendo contar con una coordinación, formación e información en las dependencias públicas que intervienen en el proceso.

— Para su correcta ejecución y lograr alcanzar los objetivos propuestos en la Ley Integral se optó por desarrollar planes periódicos de evaluación, contando con dotaciones presupuestarias para llevarse acabo.

—En la Tutela Institucional se crean dos órganos administrativos: la Delegación Especial del Gobierno 
contra la Violencia sobre la mujer, cuyo objetivo se basa en la creación de políticas públicas en relación a la violencia de género y el Observatorio Estatal de Violencia sobre la mujer, encargándose del asesoramiento, evaluaciones, pendiente de la colaboración institucional y en la elaboración de informes e investigaciones con el fin de proponer nuevas actuaciones que resulten más efectivas para atender, prevenir, sancionar y erradicar el problema.

En la Tutela Penal se anexan los tipos agravados de lesiones, incrementando la sanción penal cuando la lesión es producida contra la mujer que sea o haya estado casada con el autor, o mujer que esté o haya estado ligada a él por una análoga relación de afectividad, aun sin convivencia, o en su caso contra una persona especialmente vulnerable que conviva con el agresor (art. 153.1 CP). Además se castigarán como delitos las coacciones y las amenazas leves de cualquier clase cometidas contra las mujeres o contra las personas que se encuentren es un especial estado de vulnerabilidad.

— En la Tutela Judicial se inclinan por la creación de los Juzgados de Violencia sobre la Mujer con especial competencia en materia civil y penal y la creación del Fiscal contra la violencia de género.

La elaboración de un Plan Nacional de Sensibilización y Prevención de la Violencia de Género. 
La Ley Integral ha sido aprobada por unanimidad por todos los expertos que intervienen en el proceso, acordando que el origen y las causas de la violencia se producen bajo un contexto de desigualdad y discriminación que sufren las mujeres, y que en determinados acontecimientos el hombre utiliza la violencia como medio para demostrar su autoridad y superioridad respecto a ellas.

\section{Algunas consideraciones críticas en}

la Ley Integral (LO 1/2004)

La Ley Integral ha ocasionado diferentes debates en la sociedad realizados por expertos, desde su tramitación en el parlamento produciendo en los ciudadanos una sensibilización y compromiso de atajar la violencia de género (Camarero, 2006: 16).

Algunas de estas críticas realizadas en lo jurídico político y social con base en la Ley Integral son:

- Excluir en la creación del proyecto las opiniones de los interlocutores sociales, instituciones, organizaciones y entidades que colaboran y atienden la problemática que sufren las mujeres víctimas de la violencia de género. No haber tomado en cuenta las proposiciones de las Comunidades Autónomas en la elaboración del proyecto de ley. 
- La precipitada tramitación de la Ley Integral para enmendar el tratamiento legislativo de la violencia de género, causando desacuerdos, ya que algunos críticos señalan que no supone progreso alguno en los verdaderos y esenciales avances respecto al tratamiento legislativo establecido recientemente para contrarrestar dicha violencia: Ley de medidas concretas en materia ciudadana y violencia doméstica, la reforma del CP, y muy especialmente, la Ley que regula la Orden de Protección.

La petición del Consejo de Estado y el Consejo Escolar ${ }^{4}$ fue poner más atención en los niños porque ellos son víctimas directas de la violencia.

Dejar sin protección a los homosexuales e inmigrantes.

${ }^{4}$ Vid. Informe del Consejo de Estado de 24 de junio de 2004, sobre el Anteproyecto de Ley Orgánica Integral de Medidas contra la Violencia Ejercida sobre las Mujeres; Informe del Consejo Escolar del Estado, de 17 de junio de 2004, sobre el Anteproyecto de Ley Orgánica Integral de Medidas contra la Violencia Ejercida sobre las Mujeres.

\section{No plasma ampliamente los con-}

ceptos de violencia física, psíquica y sexual, ni se refiere a toda la violencia que están expuestas las mujeres.

Cabe mencionar en especial las controversias con mayor realce fundamentándose en dos cuestiones:

1.En el ámbito penal referente, al tratamiento penal distinto para los hombres y mujeres, aunque la conducta delictiva sea la misma, en otras palabras un mismo hecho cometido por una mujer se considera una falta (art. 153.2 CP) y cometido 
por un hombre se considera delito (153.1 CP). Provocando una agravación de la pena en función del sujeto pasivo. Algunos juristas indican que es un retroceso por lo que se ha luchado para que la ley penal se aplique con igualdad.

Motivo por el cual se presentan dudas sobre inconstitucionalidad que vulneran el principio de igualdad y la discriminación estable-

${ }^{5}$ Vid. Informe del Consejo General del PoderJudicial, sobre el Anteproyecto de Ley Orgánica Integral de medidas contra la violencia ejercida sobre las mujeres, Madrid, 24 de junio de 2004. cidos en el art. 14 CE. Respaldada esta postura por la CGPJ $^{5}$ considerando que la ley podría tener carácter de inconstitucional. Sin embargo otro sector doctrinal opina que es necesaria y justificada la aplicación de acción positiva en el ámbito penal como medida para corregir las desigualdades que han sufrido las mujeres a lo largo de la historia. Ante el planteamiento de inconstitucionalidad el Tribunal Constitucional se pronuncia en la Sentencia 59/2008, a favor de la constitucionalidad de la LO 1/2004 al considerar que la aplicación de la norma del art. 153.1 CP no va en términos de discriminación por razón de sexo sino de proteger el principio de igualdad, libertad y dignidad de las mujeres, así como combatir el origen de este tipo de violencia generada en un contexto desigualitario en el cual se aprecia un mayor desvalor en las agresiones del hombre hacia la mujer, considerando que las agresiones son más graves y más reprochables socialmente, además que la víctima ostenta una posición subordinada, por lo que en estas agravaciones se puede imponer una pena mayor para prevenirlas. Por tanto dicha regulación no afecta ningún principio constitucional. 
2. De los especiales Juzgados de Violencia sobre la Mujer, ya que se considera que no sería admisible la aplicación de la discriminación para asentar la creación de órganos judiciales que tutelan sólo los intereses de la mujer.

\section{Novedades en materia penal en la LO 1/2004}

\section{Protección contra las lesiones (art.36)}

Agravación del delito de lesiones

Antes de la reforma penal producida por la Ley Integral, el art. 148 del Código Penal contemplaba la agravación del delito de lesiones "si la víctima fuere menor de doce años o incapaz" considerándose la mayor vulnerabilidad e indefensión, dadas sus condiciones de edad e incapacidad.

Ahora la Ley Integral en su art. 36 introduce dos supuestos de agravación en el artículo 148 en sus párrafos 4 y 5 del Código Penal cuando en el delito de lesiones la víctima "fuere o hubiere sido esposa, o mujer que estuviere o hubiere estado ligada al autor por una análoga relación de afectividad, aun sin convivencia” y cuando la víctima "fuera una persona especialmente vulnerable que conviva con el autor". Castigándose estas lesiones agravadas de 2 5 años de prisión. Además de anexar en el art. 148 párrafo 2 el “ensañamiento" o la "alevosía” (Mirat y Armendáriz, 2007: 50).

Respecto a esta modificación al Código Penal estamos de acuerdo con Campos (2005: 266) atendiendo a los dos supuestos mencionados, que es válido agravar la pena del delito de lesiones atendiendo 
al resultado causado y riesgo producido en las víctimas. Por lo que consideramos que los menores de doce años, los incapaces, las mujeres y aquellas personas especialmente vulnerables que convivan con el agresor se encuentran respaldadas por la ley.

\section{Protección contra los malos tratos (art. 37)}

Cabe recordar que en materia penal los malos tratos han generado varias reformas al Código Penal, pero una de las más importantes es la Ley Orgánica del 11/2003, de 29 de septiembre, de medidas concretas en materia de seguridad ciudadana, violencia doméstica e integración social de los extranjeros por el cual se convierte en delito algunas conductas que hasta el momento eran constitutivas de falta (art. $153 \mathrm{CP}$ ).

En la nueva redacción realizada por la Ley Integral en el art. 153 del Código Penal (a través del art. 37 LO 1/2004) desaparece lo concerniente a las amenazas leves con armas o instrumentos peligrosos y trasladándolas a una mejor ubicación sistemática en el art. 171-5 dentro del Capítulo de las amenazas y en el Título de los Delitos contra la Libertad.

La modificación más significativa es la introducción de una figura específica, en el número 1 del artículo 153 del Código Penal cuando:

El que por cualquier medio o procedimiento causare a otro menoscabo psíquico o una lesión no definidos como delito o 
golpeare o maltratare de obra a otro sin causarle lesión, cuando la ofendida sea o haya sido esposa, o mujer que esté o haya estado ligada al él por una análoga relación de afectividad aun sin convivencia, o persona especialmente vulnerable que conviva con el autor.

A nuestro juicio en este apartado queda claro que la mujer es el sujeto pasivo estando casada, divorciada o haya estado ligada al autor de la conducta por una análoga relación de afectividad aun sin convivencia, o persona especialmente vulnerable que conviva con el autor.

Este delito se castiga con la pena de prisión de seis meses a un año o de trabajo en beneficio de la comunidad de treinta y uno a ochentas días y en todo caso, privación del derecho a la tenencia y porte de armas de un año y un día a tres años, así como cuando el Juez o Tribunal lo estime adecuado al interés del menor o incapaz, inhabilitación para el ejercicio de la patria potestad, tutela, curatela, guarda o acogimiento hasta cinco años.

En el artículo 153.2 del CP se encuentran el resto de sujetos pasivos que son aquellas personas a las que se refiere el art. 173.2 del CP, exceptuadas las personas contempladas en el apartado anterior de este artículo, en otras palabras se exceptúa cuando la ofendida sea o haya sido esposa o mujer, que este o haya estado ligada a él agresor, por una análoga relación de afectividad aun sin convivencia o persona especialmente vulnerable que conviva con el autor. La pena asignada a este supuesto será de tres meses a un 
año y la inhabilitación para el ejercicio de la patria potestad, tutela, curatela, guarda o acogimiento de seis a meses a tres años.

En este contexto Íñigo (2005: 39), indica que en el nuevo art. 153 Código Penal no se incluye un nuevo sujeto pasivo, por lo que estamos de acuerdo con el autor ya que en el párrafo primero no incluye a nadie que no este contemplado en el párrafo segundo remitiéndose a las personas enumeradas en el art. 173.2 del CP, y no ha sufrido cambio la agravación si el delito se lleva a cabo en presencia de menores o utiliza armas, o tiene lugar en el domicilio común o en el de la víctima, o quebrantando alguna pena del art. 48 del CP o una medida cautelar o de seguridad.

Por lo contrario el último párrafo supone una novedad al permitir imponer las penas inferiores en grado en atención a las circunstancias personales del autor y las concurrentes en la realización del hecho. Por lo que Larrauri (2008: 204) señala la necesidad de presentar atención a la aplicación que pudieran dar los jueces y tribunales al rebajar la pena en un grado, puesto que puede ser la forma más fácil de neutralizar la protección reformada que tanta polémica ha generado.

Consideramos que el artículo en mención es una de las cuestiones más importantes y controvertidas que ha presentado la Ley Integral desde sus inicios, generando debates sobre su inconstitucionalidad al suponer que los sujetos pasivos en el delito de violencia de género solo pueden serlo quien sea o haya sido esposa o mujer que esté o haya estado ligada al agresor por una análoga relación de afectividad aun sin convivencia, o personas especialmente vulnerables que convivan con el autor. 
Motivo por el cual las penas a imponer se fijan en función del sujeto pasivo. En el supuesto que el sujeto pasivo fuera una mujer o persona especialmente vulnerable, se aplicaría el art. 153.1 del Código Penal, cuya pena es de prisión de seis meses a un año o trabajos en beneficio de la comunidad de treinta y uno a ochenta días además de privación del derecho y tenencia de armas de un año y un día a tres años y si el juez lo estima conveniente para el interés del menor la inhabilitación para el ejercicio de la patria potestad, tutela, curatela guarda o acogimiento hasta cinco años (Mirat y Armendáriz, 2007: 78).

En cambio si el sujeto pasivo fuera un hombre, se aplica el art. 153.2 del Código Penal siendo la pena básica de privación de tres meses a un año y la inhabilitación de ejercer la tutela por seis meses y tres años. El resto de las penas son semejantes a las del art. 153.1 CP. Por tanto en el art. 153.1 CP se incorpora por primera vez en el ámbito penal la acción positiva y/o discriminación positiva.

\section{Protección contra las amenazas (art. 38)}

El artículo 38 de LO 1/2004 añade tres nuevos apartados numerados como 4, 5 y 6, al art. 171 del Código Penal, que regula las amenazas menos graves (falta de amenazas leves).

En párrafo 4 y 5 en el que tipifican como delitos las amenazas leves, se amplia la protección cuando el sujeto pasivo es la esposa, o persona especialmente vulnerable. En estos dos supuestos se impondrán en su mitad superior las respectivas penas cuando el deli- 
to se perpetre en presencia de menores, o tenga lugar en el domicilio común o en el domicilio de la víctima, o se realicen quebrantando una pena de las contempladas en el art. 48 de Código Penal o una medida cautelar o de seguridad de la misma naturaleza. Y también para ambos preceptos según las circunstancias del autor y del hecho podrá imponerse la pena inferior en grado.

Entonces bajo nuestra apreciación sobre la nueva regulación de amenazas leves dejan de considerarse faltas y pasan a elevarse a la categoría de delito, en el art. 171.4 del Código Penal cuando las amenazas son leves y contra la mujer que sea o haya sido esposa, o mujer que éste o haya estado ligada al autor por análoga relación de afectividad aún sin convivencia y a personas especialmente vulnerables que convivan con el autor. La pena privativa de libertad es de seis meses a un año o de trabajos en beneficio de la comunidad de treinta y uno a ochenta días.

Cabe señalar que si las amenazas leves se realizaran contra el resto de personas del art. $172 \mathrm{CP}$, serán calificadas como falta tipificada en el art. 620.2 del Código Penal, la pena correspondiente será de localización permanente de cuatro a ocho días, siempre en domicilio diferente y alejado de la víctima o trabajos en beneficio de la comunidad de cinco a diez días.

En cambio si la amenaza leve se realiza con arma u objeto peligroso y contra alguna de las personas mencionadas en el art. 173.2 CP (con excepción de las contempladas en el art. 171.4 CP), es delito del art. 171.5 CP que conlleva una pena de prisión de tres meses a 
un año o de trabajos en beneficio de la comunidad de treinta y uno a ochenta días.

En estos dos artículos mencionados observamos que se vuelve a presenciar la importancia que trae consigo el sujeto pasivo para determinar el aumento de las penas de prisión, pero se deja la misma pena por trabajos a la comunidad no importando quien sea el autor del delito.

Al respecto Larrauri (2008: 206) opina que el crecimiento de los tipos penales aplicables no puede ser la mejor política legislativa pues aumenta la inseguridad y favorece el trato desigual de casos semejantes. Frente a esta argumentación considero que se vuelve a remarcar en el artículo 171.4 y 5 (CP) el trato desigual respaldado por las acciones positivas en la ley haciendo más evidente y fortaleciendo más los planteamientos sobre su injusta aplicación desproporcionada de las penas vulnerando el principio de igualdad, motivo por el cual se tacha de inconstitucional.

\section{Protección contra las coacciones (art. 39)}

La modificación al Código Penal llevada a cabo por esta Ley Integral (art. 39) en las coacciones leves también ha producido que deje de contemplarse como falta (art. 620.1 CP) para ser delito del art. 172.2 Código Penal cuando las coacciones leves se lleven a cabo contra la mujer o esposa o persona igualmente vulnerable que conviva con el autor. 
La pena correspondiente es de seis meses a un año o de trabajos en beneficio de la comunidad de treinta y uno a ochenta días, y en todo caso, privación de derecho de tenencia y porte de armas de un año y un día a tres años. A la vez se le impondrá la inhabilitación especial para el ejercicio de la patria potestad, tutela o curatela, guarda o acogimiento hasta cinco años si resulta adecuado al interés del menor o incapaz. También se podrá aplicar la pena en su mitad superior cuando se haya perpetrado en presencia de menores, o haya tenido lugar en el domicilio común o en el domicilio de la víctima, o se hayan realizado quebrantado una pena de las contempladas en el art. 48 del Código Penal o una medida cautelar o de seguridad de la misma naturaleza. Se considerarán las circunstancias del autor y del hecho, podrá imponerse la pena inferior en grado. Si se diera el caso de coacciones leves contra las personas del art. 173.2, se considerará falta del art. 620.2 CP (modificación realizada a través del art. 41 de LO 1/2004).

\section{Quebrantamiento de condena (art.40)}

Recordando que la LO 15/2003, de 25 de noviembre modificó el Código Penal referente el quebrantamiento de cualquier prohibición de alejamiento podía ser castigado con la pena de prisión (Larrauri, 2008: 214).

La Ley Integral (LO 1/2004) modifica el delito de quebrantamiento de condena, anexando un nuevo párrafo con el número 2 del art. 468 del Código Penal que sanciona con pena privativa de 
libertad de seis meses a un año los que quebrantaren una pena del art. $48 \mathrm{CP}$ o una medida cautelar o de seguridad, cuando el ofendido sea una de las personas del art. 173.2 del Código Penal (Campos, 2005: 268).

Respecto a la finalidad de esta modificación Acale (2008: 136) opina que "no es otra que asegurarse que en todo caso los jueces tienen que imponer pena de prisión, lo que deja vía libre a la prisión provisional como medida cautelar". En este contexto Iñigo (2005: 45) señala que el quebrantamiento de condena de aquellos sujetos que han sido condenados o sospechosos de un delito de violencia doméstica son los que generan más alarma social y en atención a ello el legislador sanciona de manera especial.

En este sentido, consideramos importante convertir en obligatorio para los jueces la aplicación de una pena privativa de libertad de seis meses a un año cuando el sujeto activo quebrante la condena, con el objetivo de seguir protegiendo a la víctima en todo momento y no poner en riesgo su vida y su integridad.

\section{Protección contra las vejaciones leves (art.41)}

El art. 41 de la Ley Integral (LO 1/2004) modifica el apartado número 2 del art. 620 del Código Penal, añadiendo en la última cláusula "salvo que el hecho sea constitutivo de delito"; es decir, al haberse convertido en delitos las faltas de lesiones, las amenazas, coacción, injuria o vejación injusta de carácter leve que se lleva a cabo contra alguna de las personas referidas en el art. 173.2 CP, la 
pena será de localización permanente de cuatro a ocho días, siempre en domicilio diferente y alejado de la víctima, o bien de trabajos en beneficio de la comunidad del cinco a diez días. Cabe señalar que en estos supuestos no es exigible la denuncia de la persona o de su representante legal salvo en el caso de injurias.

\section{Aspectos procesales de la Ley Integral (LO 1/2004)}

En cuanto a las normas procesales, se encuentran ubicadas, en el Título V de la Ley Integral que corresponde a la Tutela Judicial abarcando los artículos 43 a 72, conteniendo una serie de prescripciones en mayor medida de orden procesal, cambiando el criterio tradicional de la competencia del juez con la finalidad de garantizar un tratamiento adecuado y eficaz de la situación jurídica, familiar y social-cultural de las frecuentes víctimas de violencia de género (Mayordomo, 2005: 74). Los temas procesales abordados en este Título son:

Creación de una jurisdicción especial: los Juzgados de Violencia sobre la Mujer (arts. 43 a 56), implicando importantes reformas en la Ley Orgánica del Poder Judicial y en la Ley de Demarcación y Planta Judicial.

Normas procesales civiles: perdida de la competencia objetiva cuando se produzcan actos de violencia sobre la mujer (art.57). 
Normas procesales penales: competencias en el orden penal (art. 58).

Alteración de las tradicionales reglas de competencia territorial (arts. 59 y 60).

Establecimiento de un conjunto de medidas judiciales de protección y de seguridad de las víctimas (arts. 61 a 69).

70 a 72$)$.

Podemos observar en este Título que se reitera la intención del legislador de modificar o introducir preceptos legales en las leyes del ordenamiento jurídico con la finalidad de ejercer la tutela judicial efectiva, del colectivo de mujeres víctimas de conductas violentas producidas por la lacra social.

\section{Juzgados de Violencia sobre la Mujer}

Los Juzgados de Violencia sobre la Mujer ${ }^{6}$ se basan en una jurisdicción especial destinados al conocimiento de la instrucción de las causas penales en el ámbito de la violencia sobre la mujer, abarcando además aquellas cuestiones civiles relacionadas, agrupando de esta manera el tratamiento procesal de ambas ante la misma sede, resultando una mayor eficacia en la aplicación de medidas para com${ }^{6}$ Cumpliendo con los fines de la ley in-
tegral se dictóel Real Decreto 233/2005,
de 4 de marzo, en donde se dispuso la
creación y constitución de los Jugados
de Violencia sobre la Mujer, llevándose
a cabo 17 unidades judiciales y poste-
riormente en agosto de 2005 se crearon
dos más, con sede en Madrid y en Bar-
celona. Vid. Montalbán Huertas, "La
Ley Integral de Medidas de Protección
Contra la Violencia de Género. Un ins-
trumento Novedoso", La Ley Integralde
Medidas de Protección Contra la Violen-
cia de Género, ed. Consejo del Poder
Judicial, Madrid, 2006, p. 57 . 
batir la violencia de género (Navarro, 2005: 15), entrando en funciones estos juzgados especiales el día 29 de junio de 2005 (BOE núm. 95 de 21 de abril de 2005).

Según Planchadell (2008: 281) los juzgados de violencia procuran una eficaz e inmediata protección a las víctimas de este tipo de violencia, evitando el peregrinaje ante los órganos jurisdiccionales penales y civiles, que sólo llevaría a incrementar su condición de víctima o a una segunda victimización.

Para Rodríguez (2006: 30), los Juzgados de Violencia sobre la Mujer son medidas jurídicas para cumplir con el objetivo principal de la LO 1/2004 de actuar contra la violencia que como manifestación de la discriminación y las relaciones de poder de los hombres sobre las mujeres. En este sentido, también Castillejo (2005: 8) considera que los nuevos juzgados de Violencia sobre la Mujer forman parte de una de las medidas jurídicas asumidas por el legislador para garantizar un tratamiento eficaz de la situación jurídica, familiar y social de las víctimas de violencia sobre la mujer en las relaciones intrafamiliares.

En este contexto observamos que gran parte de la doctrina considera positiva la creación de juzgados especializados con competencias penales y civiles, manifestando que es necesaria y adecuada para conseguir mayor eficacia en la actuación de jueces, fiscales y policía, al evitar la dispersión judicial, concentrando la responsabilidad en un solo juez de pronunciar la resolución de todos los conflictos y medidas concernientes a las víctimas de violencia de género (Planchadell, 2008: 279). 
Conforme al art. 43 de la LO 1/2004, se adiciona un artículo 87 bis en la Ley Orgánica 6/1985, de 1 de julio, del Poder Judicial, centrándose en los nuevos juzgados indicando que conocerán de la instrucción y, en su caso, del fallo de las causas penales en materia de violencia sobre la mujer, y de las causas civiles relacionadas, de modo que unas y otras, en la primera instancia sean objeto de tratamiento procesal ante la misma sede.

En cada partido habrá uno o más Juzgados de Violencia sobre la Mujer, con sede en la capital de aquél y jurisdicción en todo su ámbito territorial. Excepcionalmente podrán extender su jurisdicción a dos o más partidos dentro de la misma provincia. Cuando el juez aprecie que los actos puestos en su conocimiento no constituyen expresión de violencia sobre la mujer, podrá inadmitir la pretensión, remitiéndola al órgano judicial competente.

En todos estos casos está vedada la mediación en los asuntos conocidos por los Juzgados de Violencia sobre la Mujer (art. 44 de la LO 1/2004), porque en la mayoría de los casos se marca una relación de superioridad del agresor sobre la víctima haciendo dudar el posible acuerdo en el proceso.

En este sentido Magro (2007: 23) señala que la mediación no debe aplicarse porque no están en igualdad de condiciones a la hora de alcanzar un acuerdo. Por lo que sugiere que no se aplique en los juicios por delitos sexuales y en los de violencia de género por entender que la única respuesta en estos casos es la privativa de libertad, excluyendo cualquier tipo de mediación, y que el agresor cumpla pena. 
Competencia en el ámbito penal de

los Juzgados de Violencia sobre la Mujer

Apreciamos que las agresiones sobre las mujeres en la sociedad española han dejado de ser un delito invisible, produciendo inmediatamente un rechazo colectivo y una presión social y mediática para darle solución a este grave problema que se produce cotidianamente. Ante esta situación se han producido leyes para contrarrestar dicha violencia como: la LO 11/2003, de 29 de septiembre, de medidas concretas en materia de seguridad ciudadana, violencia doméstica e Integración Social de los Extranjeros; la LO 15/2003, de 25 de noviembre por la que se modifica la Ley Orgánica 10/1995, de 23 de noviembre, del Código Penal; la Ley 27/ 2003, de 31 de julio, reguladora de la Orden de Protección de las Víctimas de la Violencia Doméstica y las Leyes Autónomas.

Pero a través de la LO 1/2004, las agresiones que se producen hacia las mujeres cobran un nuevo significado de protección y atención especial, como bien lo explica esta ley en su Exposición de Motivos:

Violencia de género se manifiesta como el símbolo más brutal de las desigualdades existentes en la sociedad. Se trata de una violencia que se dirige sobre las mujeres por el hecho mismo de serlo, por ser consideradas, por sus agresores, carentes de los derechos mínimos de libertad, respeto y capacidad de decisión. 
Ante esta situación la mujer se encuentra en una posición de subordinación y dominio por parte del varón que utiliza la violencia para mantener el control y poder en las relaciones de pareja.

Ante esta situación la LO 1/2004, opta por fortalecer el marco penal y procesal, desde las instancias jurisdiccionales, iniciando con su art. 44 que incorpora un nuevo art. 87 ter en la Ley Orgánica 6/1985, de 1 de julio, del Poder Judicial para atribuir competencia a los Juzgados de Violencia sobre la Mujer, encargándose en materia penal de:

a) La instrucción de los procesos para exigir responsabilidad penal por los delitos recogidos en los títulos del Código Penal concernientes al homicidio, aborto, lesiones al feto, delitos contra la libertad, delitos contra la integridad moral, contra la libertad e indemnidad sexuales o cualquier otro delito cometido con violencia o intimidación, siempre que se hubiesen cometido contra quien sea o haya sido su esposa, o mujer que esté o haya estado ligada al autor por análoga relación de afectividad, aun sin convivencia, así como de los cometidos sobre los descendientes, propios o de la esposa o conviviente, o sobre los menores o incapaces que con él convivan o que se hallen sujetos a la potestad, tutela, curatela, acogimiento o guarda de hecho de la esposa o conviviente, cuando también se haya producido un acto de violencia de género. 
b) La instrucción de los procesos para exigir responsabilidad penal por cualquier delito contra los derechos y deberes familiares, cuando la víctima sea alguna de las personas señaladas como tales en la letra anterior. - c) La adopción de las correspondientes órdenes de protección a las víctimas, sin perjuicio de las competencias atribuidas al Juez de Guardia.

d) Del conocimiento y fallo de las faltas contenidas en los Títulos I y II del Libro III del Código Penal, cuando la víctima es alguna de las personas señaladas como tales en la letra a) de este apartado.

\section{Competencia territorial de los Juzgados} de Violencia sobre la Mujer

LO 1/2004 introdujo el nuevo art. 15 bis de la Ley de Enjuiciamiento Criminal estableciendo la competencia territorial: el domicilio de la víctima el que determina la competencia del Juzgado de Violencia sobre la Mujer, en este sentido Toro (2005: 19-20) indica que se modifica el criterio del lugar de la comisión de los hechos, hasta este momento existente, siendo por tanto necesario determinar "el lugar del domicilio de la víctima”; asimismo, la adopción de las primeras diligencias serán competencia del Juzgado de Violencia sobre la Mujer del lugar donde ocurrió el hecho, sin perjuicio de que posteriormente se inhiba a favor del Juzgado del domicilio de la víctima. Este criterio competencial se establece sin perjuicio de 
la adopción de orden de protección u otro de medidas urgentes del art. 13 de la LECrim de protección del perjudicado, que pudiera adoptar el juez del lugar de la comisión de los hechos (art. 59 LO 1/ 2004).

\section{Conjunto de medidas judiciales}

de protección y de seguridad de las víctimas

A través de la Ley Integral se pretenden reforzar los avances legislativos que anteriormente se habían producido respecto a las medidas de protección y de seguridad de las víctimas, refiriéndose en especial a dos:

La primera: al art. 544 bis de la LECrim (1999) concerniente a la orden de alejamiento que prohibía residir en determinados lugares, de acudir a determinados sitios, o aproximarse o comunicarse con determinadas personas en los casos en que se investigara un delito de homicidio, aborto, lesiones, contra la libertad, de tortura y contra la integridad moral, la libertad e indemnidad sexuales, la intimidad, el derecho a la propia imagen y la inviolabilidad del domicilio, el honor, el patrimonio y el orden socioeconómico (Moreno, 2007:32).

La segunda: en la Ley 27/2003, de 31 de julio que introduce en el artículo 13 de la Ley de Enjuiciamiento Criminal la previsión específica de que se consideran primeras diligencias y, proteger a las víctimas de violencia doméstica mediante la orden de protección, prevista en el art. 544 ter de dicha ley (Ochoa, 2007: 88), 
vista como un derecho que tiene la víctima de ser respaldada procurando su seguridad frente a posibles represiones o amenazas por parte del agresor.

En la LO 1/2004 las medidas de protección y seguridad de las víctimas las encontramos en su Capítulo IV:

El art. 544 ter LECrim se introdujo en el derecho español a través de la Ley 27/2003, de 31 de julio. Esta ley consta de dos artículos: el primero, de reforma del art. 13 LECr, posibilitando que las órdenes de alejamiento y de protección se adopten como "primeras diligencias"; y el segundo, por el que se dio contenido a un nuevo art. 544 ter LECr. Este artículo se modificó por la LO 15/2003, de 25 de noviembre, incorporando además importantes reformas en el Código a) Disposiciones Generales: medidas de protección y de seguridad serán compatibles con cualquier de las medidas cautelares y de seguimiento que se puedan adoptar en los procesos civiles y penales. En todos los procedimientos relacionados con la violencia de género, el Juez competente, de oficio a instancia de las víctimas o de sus allegados, del Ministerio Fiscal o de la Administración de la que dependan los servicios de atención a las víctimas, deberán pronunciarse en todo caso sobre la pertinencia de la adopción de las medidas cautelares y de seguimiento, y sobre su duración (art. 61).

b) La Orden de Protección: establecida en el artículo 62 de la presente Ley Integral, establece que la solicitud de adopción de la misma se efectuará ante el Juez de Violencia sobre la Mujer, o en su caso ante el Juez de Guardia; que actuarán de conformidad con lo dispuesto en el art. $544^{7}$ ter de la Ley Enjuiciamiento Criminal (regula la orden de protección para víctimas de violencia doméstica). Para que se dicte la 
orden de protección deben ocurrir los siguientes supuestos:

- Indicios fundados de la comisión de un delito o falta contra la vida y la integridad física o moral, libertad, sexual, libertad o seguridad.

- Contra personas contempladas en el art. 173.2 del Código Penal.

- Que concurra una situación objetiva de riesgo para la víctima que requiera la adopción de las medidas contempladas en el art. 544 ter LECrim.

De acuerdo con García (2006: 76), la orden de protección brinda a la víctima un estatus integral de protección, coordinada con acciones cautelares en materia civil y penal permitiendo con ello una respuesta inmediata por parte de la Administración, para brindar todo lo necesario en cuanto a instrumentos de asistencia y protección para las víctimas de violencia de género.

Cabe mencionar que la orden de protección se brinda cuando se ha iniciado un proceso penal por casos en los que se haya cometido algún delito o faltas de violencia doméstica y de género, y exista una situación objetiva de riesgo para la víctima, esto da pie a que el juez intervenga ordenando la protección a la víctima mediante la adopción de medidas cautelares civiles o penales, así como iniciar un procedimiento administrativo sobre las medidas de asis- 
tencia y de protección (Martínez, 2008: 331) social como lo estable el art. 61 antes mencionado.

A nuestro parecer la orden de protección es una medida de protección para las víctimas que denuncian la violencia de género para evitar agresiones o que vuelvan a producirse. En este proceso judicial cuentan con medidas cautelares reforzadas en materia penal y civil en atención a su especial vulnerabilidad.

c) Protección de datos y las limitaciones a la publicidad: su objetivo es proteger la intimidad de las víctimas de la violencia de género, tanto de sus familiares y allegados, pudiéndose acordar que las vistas se celebren a puerta cerrada o que las demás actuaciones judiciales se desarrollen de forma reservada (art. 63 LO 1/2004).

d) Medidas de salida del domicilio, alejamiento o suspensión de las comunicaciones: el juez podrá ordenar la salida del inculpado del domicilio familiar, impedirle regresar al mismo, aproximarse a la persona protegida fijando la distancia mínima que no podrá rebasar, ni comunicarse con las personas que se le indique, órdenes que deberá respetar y si no se llevasen a cabo recaerá en responsabilidad penal (art. 64 LO 1/2004). Estas medidas se consideran previsoras de futuros delitos de violencia de género.

e) Suspensión del derecho a la tenencia, porte y uso de armas: el juez podrá acordar, respecto de los inculpa- 
dos en delitos relacionados con la violencia de género (art. 67 LO 1/2004).

f) Garantías para cualquiera de estas medidas: puedan adoptarse mediante auto motivado en el que se aprecie su proporcionalidad y necesidad, y, en todo caso, con intervención del Ministerio Fiscal y respeto de los principios de contradicción, audiencia y defensa (art. 68 LO 1/2004).

g) Podrán mantenerse las medidas contempladas: tras la sentencia definitiva y durante la tramitación de los eventuales recursos que correspondiesen (art. $69 \mathrm{LO}$ 1/2004).

\section{Conclusiones}

Los movimientos feministas y de mujeres han insistido por (re)construir una sociedad más democrática e incluyente, fundada en la equidad, igualdad y la no violencia, donde se reconozca que la desigualdad ha sido construida y legitimada por los mandatos patriarcales y por tanto no es natural, y en la necesidad de realizar acciones positivas e integrales concretas para lograr la anhelada paridad entre mujeres y hombres, así como poner fin a la subyugación y violencia que sufren o están expuestas a diario las mujeres por cuestiones de género (la asignación de estereotipos) o misoginia.

Un claro y extraordinario ejemplo de estos movimientos sociales que reclaman la igualdad y la no violencia sin duda ha sucedido en 
España, consiguiendo que el gobierno español implementara en el año 2004 un novedoso instrumento legal para combatir la violencia contra las mujeres, por razón de género, a nivel nacional a través de la LO 1/2004 que entiende la magnitud del problema social que presenta la violencia contra la mujer y que infringe derechos fundamentales como la vida, la igualdad, la libertad, la seguridad y la no discriminación. Ante esta situación la LO 1/2004 actúa de manera integral y multidisciplinar proporcionando medidas educativas, de sensibilización, contra la publicidad ilícita, de prevención, de protección social, laboral y económica, de tutela institucional, penal y judicial, contemplando acciones positivas mediante medidas de impulso y promoción que tiene como finalidad establecer la igualdad entre los hombres y las mujeres, intentando favorecer a las mujeres sin el afán de perjudicar a los hombres que se encuentren en una situación similar. No cabe duda que a través de la Ley Integral se ha generado una extensa reforma en la legislación española, en la administración e instituciones públicas (implementando protocolos de actuación en materia), para garantizar la buena aplicación de las medidas integrales para atender, prevenir, sancionar y erradicar la violencia de género.

Asimismo se proporciona por primera vez una definición legal aplicable en toda la jurisdicción española del concepto de género considerando que dicha violencia se ejerce contra la mujer, como manifestación de la discriminación, la situación de desigualdad y las relaciones de poder de los hombres sobre las mujeres, que se ejerce sobre éstas por parte de quienes sean o hayan sido sus cónyu- 
ges o de quienes hayan estado ligados a ellas por relaciones similares de afectividad, aun sin convivencia. A nuestro juicio este concepto reconoce la violencia que ejercen los hombres sobre las mujeres en el ámbito familiar, de pareja o expareja, como consecuencia de una situación de discriminación y dominio basada en el patriarcado; es decir, la violencia se produce a consecuencia de las relaciones desiguales de poder entre los géneros y la asignación de estereotipos que favorecen lo masculino.

Cabe resaltar que el concepto de violencia de género proporcionado por la Ley Integral se introduce en el ordenamiento penal con el motivo de proteger a la mujer de esta violencia específica, realizando algunas modificaciones en el Código Penal en los siguientes artículos que son también conocidos como delitos por razón de género: art. 148 (agravación del delito de lesiones), art. 171 (protección contra las amenazas), art. 172.2 (protección contra las coacciones leves), art. 468 (quebrantamiento de condena), art. 620 (protección contra las vejaciones leves), y el art. 153.1 que consideramos el más importante ya que establece la protección de la violencia sobre las mujeres por parte de sus parejas o exparejas sentimentales, además contempla la diferencia punitiva cuando la víctima sea una mujer o un hombre. Está diferencia ha sido criticada por un sector de doctrinal que indican que se está aplicando el antiguo derecho de autor, al agravar la pena según sea el sujeto pasivo, motivo por el cual se presentan dudas sobre su constitucionalidad al decir que vulnera el principio de igualdad y la discriminación avalado por el art. $14 \mathrm{CE}$, aparte de mencionar que a los 
hombres se les está discriminando negativamente por lo que rechazan la aplicación de la discriminación positiva (acción positiva) en el ámbito penal, alegando además que es un retroceso del Derecho Penal ya que durante años se ha luchado por la igualdad de aplicación de la ley para toda la ciudadanía.

Ante este supuesto de inconstitucionalidad concordamos con la respuesta del Tribunal Constitucional (Sentencia 59/2008) al declarar constitucional la LO 1/2004, al considerar que la aplicación de la norma del art. 153.1 CP no va en términos de discriminación por razón de sexo sino de proteger el principio de igualdad, libertad y dignidad de las mujeres, ya que se aprecia un mayor desvalor (gravedad) en las agresiones del hombre hacia la mujer, por ello creemos adecuada la justificación de la diferenciación del tratamiento punitivo, determinando que la violencia de género es una manifestación de la discriminación estructural que sufren las mujeres por parte de los hombres bajo el contexto del sistema patriarcal, colocándolas en una posición de subordinación que es constitucionalmente intolerable siendo esta una justificación objetiva y razonable y que no produce consecuencias desproporcionadas en las situaciones diferenciadas en atención a la finalidad perseguida "proteger a las mujeres en sus bienes fundamentales (vida, integridad física, salud), igualdad, libertad y dignidad".

Sin embargo, a nuestro juicio, la Tutela Penal que ofrece la LO 1/2004 debería someterse a un serio estudio de reforma, debido a que esta ley ha dejado de lado la protección en los casos de violencia de género cuando suceden bajo el contexto de las detenciones ilegales, 
privación de la libertad, la libertad sexual, cuando la víctima este embarazada, etc.; por ello es necesario introducir en estos supuestos el plus de protección ante las agresiones masculinas que sufren o están expuestas las mujeres, significando con ello, ampliar la protección contra esta violencia extrema hacia las mujeres, así como la modificación al Código Penal y que pasarían a formar parte del tratamiento punitivo por los delitos cometidos por razón de género.

Por último, consideramos un buen acierto las medidas cautelares de protección reforzadas en materia penal y civil, en atención al estado de vulnerabilidad de las víctimas con el objetivo de evitar que se (re)produzca el ciclo de la violencia, brindar mejor seguridad y atención integral a las afectadas y a sus hijo/as través de las instituciones y su personal cualificado y sensibilizado en materia. Asimismo los Juzgados de Violencia creemos que son imprescindibles para agilizar los procesos judiciales en materia penal (denuncia por delitos de violencia de género, girar ordenes de protección, etc.) y civil (divorcio, pensión alimenticia, patria potestad, etc.) y evitar la doble victimización.

Por todo ello, la Ley Integral (LO 1/2004) se ha posicionado como referente europeo y mundial para atender, sancionar, prevenir y erradicar la violencia de género.

\section{Bibliografía}

ACALE SÁNCHEZ, María (2008). "La perspectiva de género incorporada al Código Penal a través de las reformas que ha sufrido tras la aproba- 
ción de las leyes orgánicas 11 y 15/2003 y 1/2004", Violencia de Género y Sistema de Justicia Penal, Villacampa Estiarte (Coord). Valencia: Tirant lo Blanch.

AÑón RoIG, María José (2005). "Violencia sobre las mujeres, discriminación, subordinación y derecho”. En BoIX ReIG, Javier y MARTínez García (Coord.). La nueva ley contra la Violencia de Género, Madrid: Closas-Orcoyen.

ARAgOneses MARTíneZ, Sara (2006). "Las medidas judiciales de protección y de seguridad de las víctimas de violencia de género", Tutela Penal y Tutela Judicial Frente a la Violencia de Género. Madrid: Colex.

Camarero Benito, Susana (2006). "Ley Orgánica 1/2004, 28 de diciembre, de medidas de protección contra la violencia de género". En Montealbán Huertas (Coord.). La Ley Integral de Medidas de Protección Contra la Violencia de Género, Madrid: Consejo General del Poder Judicial.

Campos Cristobal, Raquel (2005). "Tratamiento penal de la violencia de género”. En Borx ReiG, Javier y Martínez García (Coords.). La nueva ley contra violencia de género. Madrid.

Castillejo Manzanares, Raquel (2005). "Cuestiones que suscita la Ley Orgánica de Medidas de Protección Integral contra la Violencia de Género", Diario La Ley, núm. 6290, jueves 7 de julio de 2005. En línea. Disponible en www.laley.net

Código Penal español

CONSTITUCIÓN ESPAÑOLA

García Ortiz, Lourdes (2006). "Medidas Judiciales de Protección y Seguridad de las Víctimas en la Ley Integral. Cuestiones Derivadas de su 
aplicación e integración con el resto de medidas cautelares previstas en el ordenamiento", La Violencia de Género: Ley de Protección Integral, implementación y estudio de la problemática de su desarrollo. Madrid: Consejo General del Poder Judicial, Cuadernos de Derecho Judicial.

IBÁÑEz Solaz, María (2007). "La Ley Orgánica 1/2004, de 28 de diciembre”, Violencia de Género Perspectiva Multidisciplinar y Práctica Forense, Directores Rivas Vallejo/Barrios Baudor. Navarra: Thomson Aranzadi. InForme del Consejo General del Poder Judicial, sobre el Anteproyecto de Ley Orgánica Integral de Medidas contra la Violencia Ejercida sobre las Mujeres, Madrid, 24 de junio de 2004.

INFORME DEL CONSEjo De EsTADO, sobre el Anteproyecto de Ley Orgánica Integral de Medidas contra la Violencia Ejercida sobre las Mujeres, Madrid, 24 de junio de 2004.

INFORME DEL CONSEJO Escolar DEL EsTADO, sobre el Anteproyecto de Ley Orgánica Integral de Medidas contra la Violencia Ejercida sobre las Mujeres, Madrid de 17 de junio de 2004.

Íñıgo Corroza, Elena (2005). "Aspectos Penales de LO /2004, de 28 de diciembre", Comentarios a la Ley Orgánica de Protección Integral contra la Violencia de Género. Aspectos Jurídicos Penales, Procesales y Laborables. Navarra: Thomson Aranzadi.

JuÁrez MelÉndez, Inmaculada (2002). Secretaria General de la Federación de Asociaciones de Mujeres para la Democracia de Madrid: Informe de la ponencia sobre la erradicación de la violencia doméstica, constituida en el seno de la Comisión Mixta de los Derechos de la Mujer, Boletín de las Cortes Generales, viI Legislatura, Actividades Parlamentarias 4 de diciembre de 2002. 
KaUfman, Michael (1989). Hombre: placer, poder y cambio. República Dominicana: Cipa.

Larrauri, Elena (2008). Mujeres y Sistema Penal, Violencia Doméstica. Argentina: Euro Editoriales.

LAGARDE, Marcela (1990). La identidad Femenina. México: PUEG-UNAM.

Ley de ENJUiCiamiento CRiminal (LECrim)

Ley General de Seguridad Social y Estatuto de Trabajadores

Ley de Demarcación y Planta Judicial

LEY ORGÁNICA 3/2007, de 22 de marzo, para la Igualdad Efectiva de Mujeres y Hombres.

-1/2004, de 28 de diciembre, de Medidas de Protección Integral contra la Violencia de Género (LO 1/2004).

—15/2003, de 25 de noviembre, por la que se modifica la LO 10/1995, de 23 de noviembre, del Código Penal.

11/2003, de 29 de septiembre, de medidas concretas en materia de Seguridad Ciudadana, Violencia Doméstica e Integración Social de los Extranjeros

Ley 27/2003, de 31 de julio, reguladora de la Orden de Protección de las Víctimas de la Violencia Doméstica

Ley 1/1996, de 10 de enero de Asistencia Jurídica Gratuita

Ley Orgánica 6/1985, de 1 de julio, del Poder Judicial

Magro Servet, Vicente (2007). "La ausencia social al poder judicial regula la mediación penal al probar que es eficaz”, Periódico de Alicante, Noticia de 25, noviembre de 2007. En línea. Disponible en www.diario información.com 
Martínez Gallego, Eva. (2005). Ley de Medidas de Protección Integral contra la Violencia de Género, Comentarios Breves, Sanz Mulas/Gonzáles Bustos/Martínez Gallego (Coords.). Madrid: Iustel.

Martínez García, Elena (2008). "La protección cautelar penal de las víctimas de violencia de género". En Villacampa Estiarte, C. (Coord.). Violencia de Género y Sistema de Justicia Penal, Valencia: Tirant Lo Blanch.

Mayordomo Rodrigo, Virginia (2005). La Violencia Contra la Mujer un estudio comparado. Madrid: Dilex. S. L.

Montalbán Huertas, Inmaculada (2006). "La Ley Integral de Medidas de Protección Contra la Violencia de Género. Un instrumento Novedoso", La Ley Integral de Medidas de Protección Contra la Violencia de Género. Madrid: Consejo del Poder Judicial.

Mestre, Ruth (2005). "Violencia sobre las mujeres, discriminación, subordinación y derecho". En Boix Reig y Martínez García (Coord.), La nueva ley contra la Violencia de Género. Madrid: Closas-Orcoyen.

Mirat Hernández, Ma. Pilar y Armendáriz León, Carmen (2007). Violencia de Género Versus Violencia Doméstica: Consecuencias Jurídico. Madrid: Difusión Jurídica y Temas de Actualidad, S.A.

Miranda NaVArRo, Eduardo (2005). "Los nuevos juzgados de la violencia sobre la mujer y las reformas sobre las secciones de las audiencias provinciales”. En Velázquez Martín, Á. (Coord.), Los juzgados de violencia contra la mujer. Madrid: Signum.

Moreno Catena, Víctor (2007). "Medidas Judiciales de Protección y Seguridad de las Mujeres Víctimas de Malos Tratos”. En GómeZ 
COLOMER (Coord.), Tutela Procesal frente a hechos de violencia de género. Ed. Universitat Jaume I.

Muerza EsparzA, J. (2008). Aspectos procesales de la LO 1/2004, de 28 de diciembre, Comentario a la Ley Orgánica de Protección contra el delito. Valencia: Tirant lo Blanch.

Ochoa Castellanos, Ana (2007). "Los juzgados de violencia sobre la mujer y su relación con el juzgado de guardia”, La Violencia de Género: aspectos penales y procesales. Sevilla: Universidad de Sevilla.

Palomar Olmeda, Alberto (2005). "Información Estadística y Registros. Oficinas de Atención a la Víctima de Delitos Violentos y Ley Integra”, La Administración de Justicia en La Ley Integral Contra La Violencia de Género. Madrid: Ministerio de Justicia.

Peramato Martín, Teresa (2007). Fiscal del Tribunal de Justicia de Madrid para la Sección de Violencia de Género de Madrid, "La violencia de género como manifestación de desigualdad" Curso: mujer, igualdad y derecho, Centro de Estudios Jurídicos, Madrid 25 y 26 de junio de 2007.

Pérez López, Juan Carlos (21/08/2008). "Contra el maltrato, más leyes", Periódico, El País.

Planchadell Gallardo, Andrea (2008). "La competencia de los juzgados de violencia sobre la mujer”. En Villacampa Estiarte, C. (Coord.), Violencia de género y sistema de justicia penal. Valencia: Tirant lo Blanch.

REAL DeCRETo 233/2005, de 4 de marzo, en donde se dispuso la creación y constitución de los Jugados de Violencia sobre la Mujer.

RED DE ORGANIZACIONES FEMINISTAS CONTRA LA VIOLENCIA DE GÉNERO (2001). "Una larga batalla de las organizaciones de mujeres: Necesidades y 
objetivos de esta Ley”. Madrid. En línea. Disponible en www.red feminista.org

RodríGuez LaINZ, José Luis (2006). Juzgado de Violencia sobre la Mujer y Juzgado de Guardia. Barcelona: Bosch.

Sanz-Díez de Ulzurrun, Jaime y Moya Castillo, Manuel (2005). Violencia de Género, LO de Medidas de Protección Integral Contra la Violencia de Género. Barcelona: Ediciones Experiencia.

Sentencia TC 59/2008, a favor de la Constitucionalidad de la LO 1/ 2004.

Toro PeÑA, Juan (2005). "Los Nuevos Juzgados de la Violencia sobre la Mujer y las Reformas sobre las Secciones de las Audiencias Provinciales", En Velázquez Martín, A., (Coord.), Los Juzgados de Violencia sobre la Mujer. Madrid: Signum. 